\title{
Formal three-dimensional computational analyses of archaeological spaces
}

\begin{abstract}
This paper focuses on the use of formal three-dimensional computational analyses of archaeological spaces as a means to enhance archaeological interpretations, which are usually constrained by the nature of the archaeological record and the methodologies employed during all stages of knowledge production. The first part of this chapter concentrates on the potential of lighting analysis to identify the impact that illumination has on the perception of a given environment and task performance. The second part explores built space, focussing on patterns of visibility, based on texture viewsheds methodology. All the examples presented in this paper come from three different types of spaces in Minoan Crete (a house, a workshop and a burial building), providing valuable information about different aspects of everyday life in 3000-I600 BCE. Formal visibility and lighting analysis techniques, based on three-dimensional computer graphic simulations, provide a synthetic understanding of the potentials of these spaces, stimulating discussion of visual perception, as well as of a broader spectrum of senses.
\end{abstract}

\section{Introduction}

It is common practice within interpretations of archaeologically attested environments to develop spatially-contingent conclusions. Thus, in discussing motion within space one might consider a series of rooms acting so as to direct movement, to focus attention, and to provide sensations of enclosure and control. Such interpretations commonly derive from experience of the surviving spaces, examination of correlating what are perhaps better preserved environments, and consultation of plans and elevations. Computer graphic simulation has built on the potential of conventional painted and drawn reconstructions to provide access to hypothesised three-dimensional environments. These in turn stimulate critique and an emotional or purely functional engagement with visualised spaces (Earl et al., in press; Beale et al. 20I0).

More recent developments in computational practice have made available easily accessible tools that can formalise the interaction with these simulations. Thus, architectural design software enables calculation of exact movements and transformations of natural light around built spaces and landscapes and the impact of varying forms of artificial illumination. Alongside this, formal analyses of visibility enable the practicalities of the illumination of a given space to be compared to the potentials afforded by movement around it for viewing given locations. Together these formal methods provide a counterpart to less formalised modes of visual interpretation.

In this paper we concentrate on the potentials of formal lighting analysis to identify the illumination that has an impact on the perception of a given environment. We highlight the 
importance of virtual constructions (for the use of this term cf. Papadopoulos and Kefalaki 20I0) in archaeological research, especially concerning the estimation of lighting values in ancient structures and the importance of natural and flame light in domestic, religious and working spaces. We then consider ways of exploring the visibility of the space as a whole, and in the context of the available light and of computer graphic visual simulations of the environment as it is perceived. All the examples that will be presented below come from Minoan Crete, with attention focussed not on the palatial structures that characterise many studies in the area, but rather on three different types of spaces: houses, workrooms and burial buildings, which provide valuable information about private life, working conditions and religion respectively. We leave for a later publication considerations of what the subsequent perception of digital objects within these simulated environments might mean in archaeological terms.

\section{Illumination of computer graphic simulations}

The interaction between people and objects in space is fundamentally mediated by light. As these relationships are at the core of what archaeological practice seeks to do, so must illumination be a fundamental factor in understanding past societies. Contemporary Western lifestyles are based on the ubiquity of artificial illumination and constructed landscapes conditioned to available sunlight, to the extent that these have become an accepted background to our daily lives. In the past, evidence for artificial illumination suggests that it required greater effort to create and deploy, and was more variable and generally less successful in providing functionally useful illumination. Nevertheless, natural sunlight coupled with this variety of flame lights facilitated aspects of daily routine, including work and rituals (Parisinou 2007). Light enables agents to extract valuable information from their environment, while eliminating visual discomfort and also causing diverse experiences, attitudes and expectations (Boyce 2003).

In modern architectural design light is closely related to the proposed activities associated with specific spatial orientations. In archaeologically defined environments it is similarly important to distinguish well-lit and darker areas and to consider the potential activities in each case. Visualising and analysing the illumination of particular areas and structures can therefore contribute to the development of hypotheses of functional use, and an evaluation of their impact. Furthermore, light is a crucial factor in providing the character peculiar to a given environment, defining to a great extent the ways in which it is perceived. In exploring such information we do not underestimate that visual acuity - comfort and discomfort - and task performance are influenced by many physical and social variables, and not solely by the amount of light in an environment. Similarly we do not associate given perceptual stimuli such as colour and form with emotional, aesthetic responses. Rather, the analysis of the lighting and the simulation of its impact within a given context is 
considered to be an additional data type inherent in the archaeological record, but rarely exposed for analysis.

As already indicated in numerous finds from prehistory, the role of illumination in ancient structures was of great concern. People were producing terracotta lamps, either to use them in areas such as storerooms and workshops or for various activities, such as gatherings and rituals. In addition, sunlight had an integral role in these practices. Both uses are documented in ancient literature, inscriptions, presentations of light on pottery and sculpture as well as physical remains found in several excavations, either in private houses, working areas or sanctuaries. However, the understanding of illumination in prehistoric times is more complicated, since physical remains are far less in quantity and preservation in comparison to subsequent eras, and written sources do not exist to provide an indication of people's intentions.

Apart from the physical construction of ancient structures, we are limited in our options for finding reliable means for estimating the contribution of illumination to people's lives. In most cases, it is impractical to build replicas of such physical constructions due to the high quality and quantity of construction materials to be employed, the skills that modern workmen need to construct the buildings using the methods of the past, the high level of scientific expertise required, and consequently the greater cost involved. Three-dimensional computer models can be used to replicate many of these components, but with reduced overheads in some areas. It is still essential that simulated buildings conform to appropriate structural principles and precedents, and that the attendant light sources interact physically with the materials employed. However, the cost of physical labour and materials is translated into one of modelling, architectural expertise and hardware and software resources. In addition such virtual buildings make possible infinite variety and hence a potentially broader and better examination, interpretation and narration of the past.

Computer-based visual simulation of past environments takes one of two broadly divergent approaches. The first uses geometry, textures and simple, multiple light sources to replicate the visual appearance of a real environment. The modelling process is structured around an expected visual product. This is the approach common to film and television graphics. In our own workflow and that employed in architectural design the emphasis is on physical realism (Earl et al., forthcoming a). In a physically real simulation the pattern of light, colour and shade observed is a function of the input-simulated light energy and the properties of the objects with which it interacts. Such an approach requires greatly increased computational resources and also more detailed knowledge of the input data. For example, few archaeological simulations make use of physically accurate properties, since research regarding combustible materials is still in preliminary stages and remains quite problematic, especially for specific fuels such as wood. 


\section{Previous work}

Much of the work in physically accurate simulation of ancient lighting has been undertaken by Chalmers (2002) and Devlin (2001; 2002). They examined the realistic visualisation of archaeological site computer graphic simulation based on experimental archaeology and physics. In addition, Ioannis Roussos (2003a; 2003b), working in the same group, made a comprehensive study of small-scale flames and different fuel types, using his own scientific and psychophysical investigations. Other work in the domain includes that by Sundstedt on the ancient Egyptian temple of Kalabsha (Sundstedt et al. 2004), Masuda and Yamada (2004) on Sunlight Illumination Simulation in Fugoppe Cave and Eva Zányi (2007) on flame illumination of Byzantine Art in Cyprus. Most of this work focused on the perceptual differences of archaeological sites lit by different types of lighting. It did not focus on the ability of formal lighting analysis to calculate the amount of light in an ancient environment and to understand the intended content of an environment on this basis.

A pioneering paper that considers ancient lighting in terms of energy transmitted to given locations is Dawson et al. (2007; cf. also Dawson and Levy 2005). They not only simulated flame light sources, but also used the results to interpret the archaeology of Arctic dwellings on the basis of the tasks that may have been performed in their interior. Our work on the computer graphic simulation and lighting study of the Minoan cemetery at Phourni, Crete (Papadopoulos 2010; Papadopoulos and Earl 2009; see below) built on this. This work produced a series of alternative computer graphic simulations and considered how these may have affected the perception of the sites in conjunction with the lighting values obtained. It also used these values for natural and flame light to interpret the archaeology of the site and discuss theoretical issues regarding death management in Minoan Crete. The work at Zominthos' ceramics workshop (Papadopoulos and Sakellarakis 2013; see below) followed the same principles. Here the lighting analysis rejected the initial interpretation of the room as a workshop.

Happa's work for Panagia Angeloktisti (2009) includes accurate incorporation of Image-Based Lighting, High Dynamic Range Environment Maps of photographs and interpolated spectrophotometer data collected on site. His STAR paper presented in VAST2009 (2009) also comprises a summary of virtual construction and illumination studies completed to date, mainly regarding the use of modelling tools, technical approaches and methodologies. In CAA20Io Dobbins and Gruber (2013a, 2013b) presented a virtual presentation of the Drinking Contest at Antioch and also of the House of the Faun in Pompeii. In both projects, they simulated how light shifted throughout the hours of the day or days of the year, to observe when mosaics would have been exposed to direct sunlight or were in the shade, trying to consider the impact on how we perceive the artworks within the buildings in contrast when they are displayed in museum exhibitions. In VAST2oro Callet and Dumazet (2010) presented a paper about natural lighting in Notre Dame Cathedral in Paris, considering its influence on gilts and polychromy. This research, mainly based on 
spectral simulation, helped towards a further understanding of what could be the medieval design of interior lighting schemes. The authors (Earl et al., forthcoming a) have also worked on the lighting analysis of the Basilica Portuense at Portus, discussing both the functional and metaphysical role of illumination. Lastly, Frischer and Fillwalk, in CAA2OI2 (forthcoming), presented a lighting simulation for the path of the sun on any time and day of the year I30 CE at Hadrian's Villa, Italy. They particularly focused on the solar alignments affecting the design and orientation of the Temple of Apollo in the Accademia and the lower rotunda of Roccabruna.

\section{Lighting study one: the Minoan cemetery at Phourni - Burial Building 19}

Contemporary and archaeological evidence suggests that light is of great significance in religious contexts, with its symbolism pervading the geography of sacred landscapes. It is for this reason that a lighting study was undertaken at the Minoan cemetery at Phourni. Existing theories relating the orientation of the buildings and natural illumination to the perception of life and death by the living were critically examined as part of a broader examination of the role that natural and flame light might have played during specific funerary rites.

The position of the sun and hence the natural illumination of the buildings at Phourni is a function of the orientation of the structures towards north, their geographic location, and the date and time. It is widely accepted that the orientation of the structures had some connection with specific beliefs about the dead. For example, the east-facing tombs may be closely related to the rising sun, as this could only have entered the interior on particular days of the year. However, a definitive answer remains elusive (Blomberg and Henriksson 2002). The purpose of the computer-based simulation of Phourni was therefore to examine the impact of natural and flame light in the interior of the burial structures and to discuss its impact when, for example, corpses were admitted into the tombs, or when post-funerary or other rituals were taking place.

The ground plan of BBig is rectangular externally and apsidal internally, with its apse on the east side (fig. I). Most of the walls, except for the west, are unusually thick for the size of the building, and also reinforced by a huge monolith at the south side and southeast corner. However, the structure, as it is today, does not exceed a height of one metre, having a doorway, c. $0.8 \mathrm{~m}$ wide, at the northwest corner. The plan of the structure is broadly representative of the architectural features of other well-known house tombs of the period. These were intended to copy the houses of the living, and hence to serve as "houses for the dead" (Soles I992).

The most controversial issue concerning the original form of Burial Building ig is the way that it was roofed. In I994, Maggidis, drawing on his study of the assemblage, and following the excavator's observation regarding the construction of the east wall with stones 
forming a slight overhang (Sakellarakis and Sakellaraki 1976), published a hypothetical illustration of the building (Maggidis I994). The roof was presented as a semi-vault, based on the north, south and east walls, and closed on the west side by a thin, vertical west wall. The idea of a semi-vault, although peculiar, cannot be totally rejected, since there is no direct evidence to suggest any alternative. Due to the absence of relevant data suggesting possible roofing techniques, it was decided to construct several alternative versions of this structure (fig. 2). Although they do not have any impact on the available space in the burial building, they affect not only the visual perception of the structure, but the lighting as well, as the height and the materials of the building change.

\section{Results}

The software employed in this and the subsequent analyses was 3 ds Max Design. This includes a set of lighting analysis tools tailored to the needs of architects and lighting designers. The tools available allow a simulation to be produced of a given environment in which energy is accurately conserved. In other words, as light from the sun or other luminaires enters the scene it has a specific energy which can only decrease as it is progressively reflected by and refracted through the objects, people and architectural features that it encounters. Lighting analysis provides metrics for the amount of light arriving at a given point in space (the illuminance measured in lux and correlated to the human perception of what is commonly called brightness) and for the amount of light reflected back from it (the luminance measured in candelas per square metre). The difference between these will be a function of the incident direction and wavelength of light and the properties of the material it encounters. The direct illuminance can be calculated for objects in the path of light sources such as a wall in direct sunlight. The indirect illuminance can be calculated for objects that are not directly illuminated, receiving the energy bounced off one or more intermediate surfaces.

For a lighting analysis to be accurate there are a number of key requirements. First, the geometry used must be carefully and accurately produced and must conform to a number of technical norms. Second, the orientation and location of natural and artificial luminaires must be correct. Where scenes take account of natural lighting this will include values impacted by atmospheric effects such as low-level cloud. Third, the energy and distribution pattern produced by the luminaires must match those in the real world. Fourth, the quality of the lighting solution produced by the computer must be high. Approximation is a necessary factor in the simulation of light transport, as any given scene would under normal conditions contain far more photons than could ever be directly simulated. The means of approximation chosen and the quality parameters associated with it have a direct impact on the physical accuracy of the lighting analysis. For this reason we are increasingly using the University of Southampton's Iridisz supercomputer and high performance workstations to 
generate simulations, particularly where it is necessary to consider a number of geometric and lighting permutations. At the time of writing Iridis 3 is the fastest Windows computer in Europe, with up to 8000 cores available for processing. In our experiments we have identified considerable variations in lighting simulation outcomes as a consequence of changed indirect illumination settings. These do not define a linear relationship, however, as they are entirely subject to the material and geometric properties present in the scene. We opt for using the most detailed options whenever possible.

The final impact on lighting analysis results from the surface materials used. These must as closely as possible mimic the interaction between light and the real-world material they represent. For example, a darker coloured material will contribute less indirect illumination to a scene than a lighter material. It will have no impact on the direct illumination. A material with a glossy finish will contribute more to the indirect illumination than a matte finish. A rubber object will contribute more light to the scene than a leather one. An opaque object will contribute more light energy than a transparent one, if the transparency allows the light to escape from the area of the analysis. The impact of this material variation will be evidenced in the changing illuminance values associated with objects receiving lighting bounced off the object with the given material, and in the varying luminance value directly observed of the object itself. In designing modern buildings the architect has the benefit of a host of available luminaire types, which include experimentally derived energy and distribution values. In an archaeological context we are dependent upon more sporadic capture of such data and on the ad hoc modification of tools and resources designed for architects. Thankfully there is increasing work in this area for artificial luminaires. In the case of natural lighting the existing standards for dealing with sunlight and skylight (e.g. the Commission Internationale de l'Éclairage (CIE) sky models) provide an effective framework, coupled with tools for calculating ancient sun positions via astronomical ephemeris tools.

At Phourni the results clearly demonstrate the potential of this lighting analysis approach. The southwest orientation of BBig suggests that during the morning hours of the months considered as part of the analysis (July and October) its interior is weakly lit, with the maximum amount of illuminance in most of the cases under fifty. During the afternoon, it is illuminated by direct and indirect light, which significantly increases the interior illuminance values by more than five hundred per cent. It is also interesting that although the solstices and equinoxes tested do not present any features suggesting that these dates may have been considered to be 'times of the dead' (Goodison 200I), sunlight penetrates directly into the interior during specific hours of the day, especially between three and six in the afternoon.

Although it is not feasible to draw a definite conclusion from these results, it can be supposed that as it is the case of regular tombs, it may have been an important time of the day, for either the dead or the living. However, the fact that direct light enters BBig and the other tomb modelled, Tholos $\mathrm{C}$, at different times of the day is indicative not only of the different orientation of the structures, but of its relation to symbolic aspects of beliefs about 


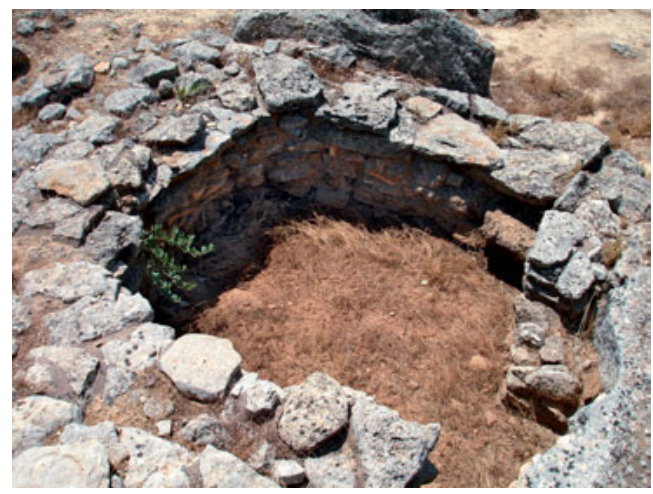

Figure 1 | Burial Building I9 in its current state of preservation from the North West.

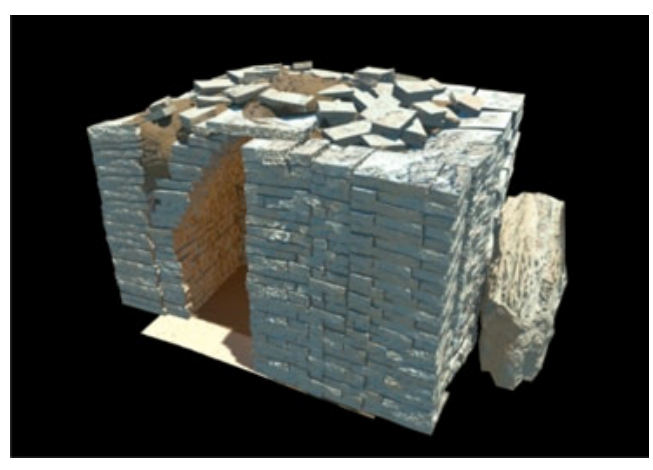

Figure 2 | One of a number of hypothetical constructions of Burial Building I9, which presents the only method of construction of a vaulted roof in order for it to be stable. View from the South West. The exterior is rectangular, the interior forms a semi-vault and the gap between the two is filled up with a large amount of earth and stones. The west wall does not exceed I metre.

death and the afterlife. Although these beliefs are unknown to us, it is feasible to associate them with the careful treatment of the body during primary burials, suggesting that after death and before decomposition, individuals may not have been considered to have gone from the world (Parker I999). Thus, the rising sun entering into the tomb may have been indicative of a life force which helped them in some way. On the other hand, as is the case with Burial Building I9, the light of sunset entering into the structure, which was probably used as an ossuary rather than a tomb, as well as the subsequent gradual increase in darkness, may have symbolised the passing of time and the ending of life. The results from the lighting study do not on their own provide any direct evidence for a different use of Building I9 other than as a tomb. They can, however, be used to facilitate a useful discussion about any potential connection of sunrise and sunset with construction decisions, linked to the use and the probable meaning of the burial buildings.

Since considerable uncertainty remains about the original architectural form of the building, there are concomitant uncertainties relating to the lighting analysis. The illumination of the interior is increased or reduced depending on the architectural features that are added or removed. However, according to the lighting analysis values the amount of light entering the tomb seems enough for such a small place for most hours of the day, and 

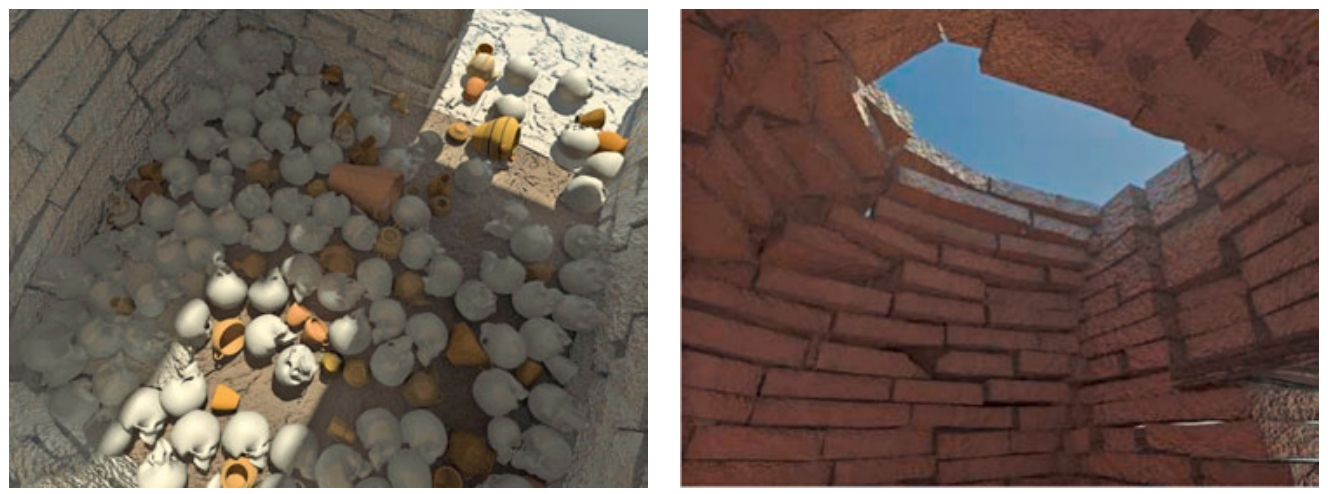

Figure 3 | The interior of Burial Building is during its first phase on 30 th July 2007 at 3 p.m., lit by direct and indirect sunlight through the doorway and the roof. Illuminance values exceed 600 lux (red colour).

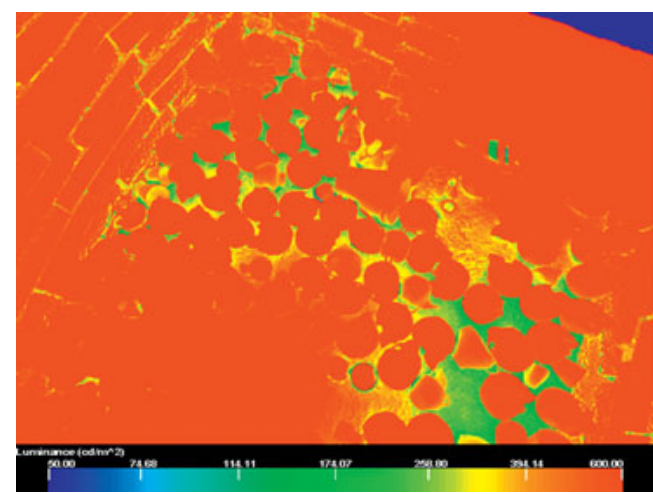

suggests an intention to create a building to be used not as a tomb, but to facilitate the better organisation of the ritualised secondary treatment of the dead (Papadatos 1999). It is not possible to reliably assess how the lighting in the interior was changing when more depositions and offerings were introduced, as certain aspects of rituals change very quickly, and in non-linear directions, sometimes leaving no visible mark. However, the accumulation of the depositions at the entrance gradually reduced the amount of light reaching the interior, although this remained well lit during most of the daytime. As can be clearly seen in the lighting analysis images, the luminance values have been significantly reduced in comparison to the first phase, during which the interior was receiving values of more than 400500 lux (figs. 3 and 4a, b). However, the latter could not have any impact on the various practices taking place in the interior, as the lighting values are at an average level by modern standards, which may suggest that flame lighting was only needed early in the morning and during the night (fig. 5). However, ritual fires or other ceremonies under flame illumination cannot be excluded (Papadopoulos and Earl 2009; Papadopoulos 2010). 

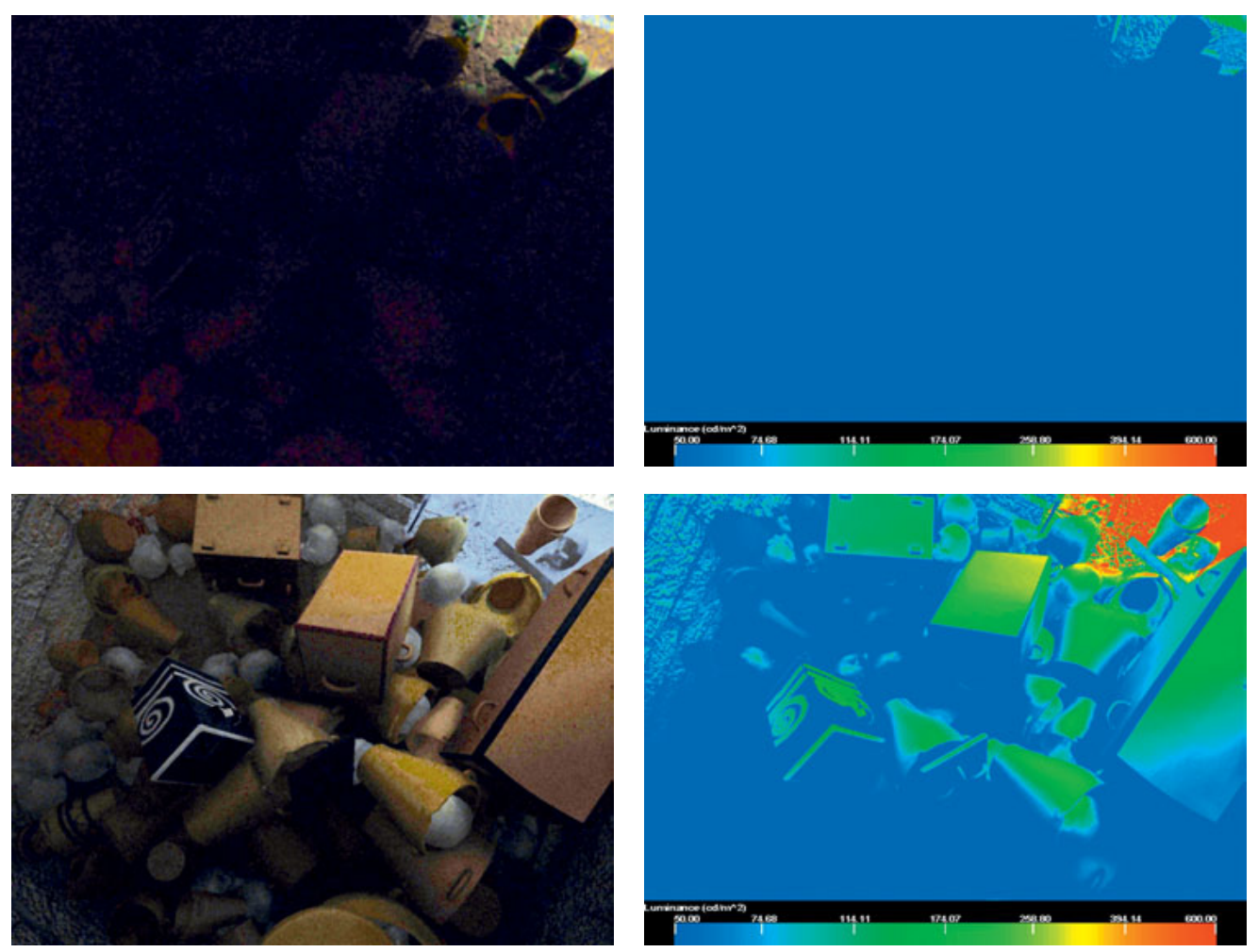

Figure 4a | Second phase of Burial Building I9. First Row: 3oth July 2007 at 7 a.m. Rendered output indicates almost absolute darkness during the tested date. Luminance values not exceeding $50 \mathrm{~cd} / \mathrm{m}^{2}$. Second Row: 30 th July 2007 at I2 p.m. Lighting values range between $\circ$ to $200 \mathrm{~cd} / \mathrm{m} 2$ in lower and upper parts of the burial building accordingly.

\section{Lighting study two: Kommos, a Minoan harbour - the North House}

The Hilltop houses at the Minoan harbour of Kommos were virtually constructed with a particular emphasis on House N. This is a two-storeyed structure, and the largest residence excavated on the hilltop. The house is characterised by an orderly plan with a consistent orientation of the walls to the cardinal compass points and with spacious interior areas. All exterior facades have been traced, the only uncertain one being on the north. It is the largest known Late Minoan house on the hill at Kommos, and is also one of the better built and apparently more prosperous houses in that area of the settlement (Shaw and Shaw I996).

Although the primary focus for this case study was to graphically simulate the Hilltop houses according to the excavated data and similar archaeological correlates, it was also interesting to examine the lighting conditions under which the inhabitants were preparing food, sleeping, receiving visitors and to discuss to what extent there are similarities and dif- 

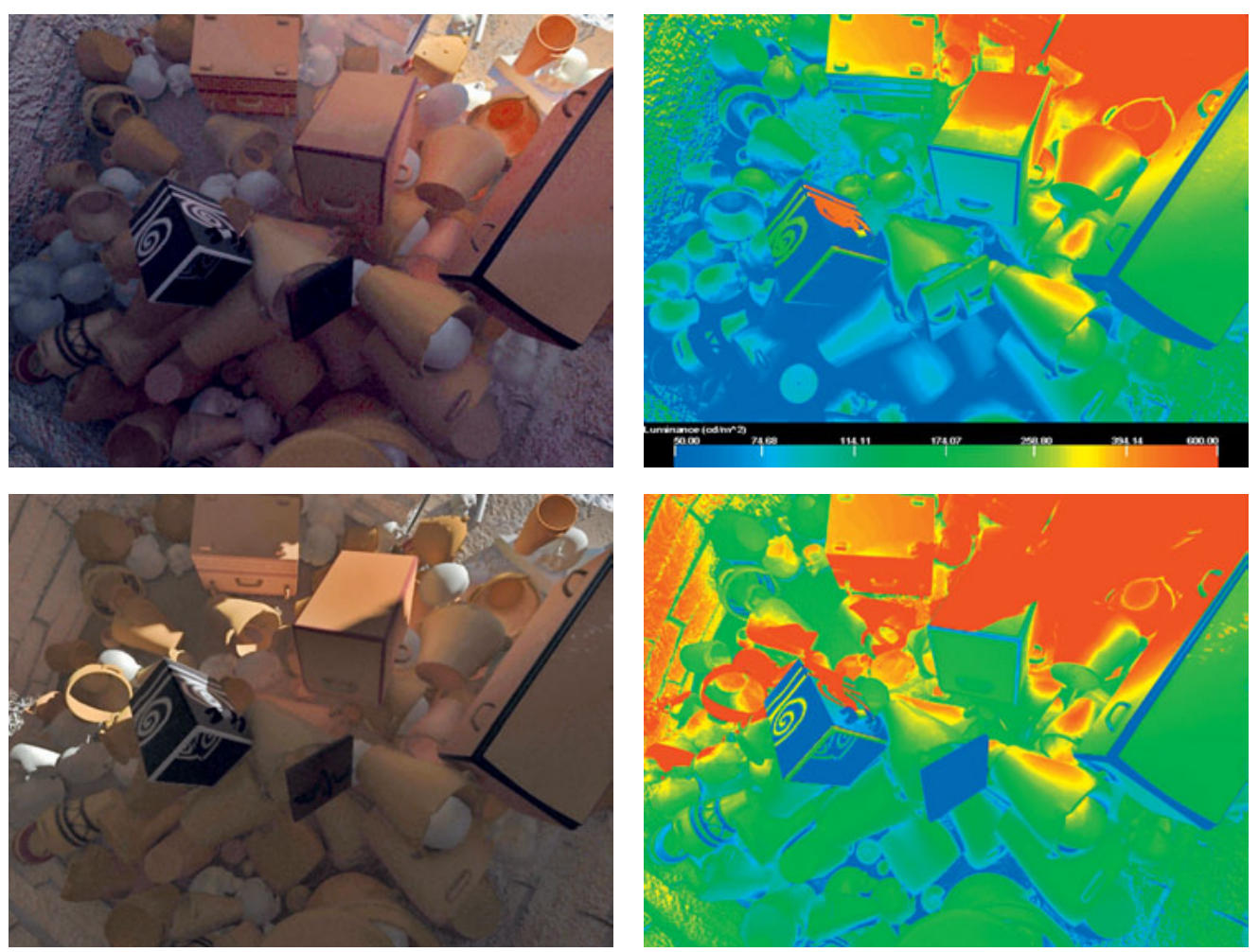

Figure $4 \mathrm{~b}$ | Third Row: 30 th July 2007 at 3 p.m. Lighting values range between 50 to $300 \mathrm{~cd} / \mathrm{m}^{2}$ in lower and upper parts of the burial building accordingly, while values exceed $600 \mathrm{~cd} / \mathrm{m}^{2}$ at the area close to the opening. Fourth Row: 30 th July 2007 at 6 p.m. Luminance values in $\mathrm{cd} / \mathrm{m}^{2}$.
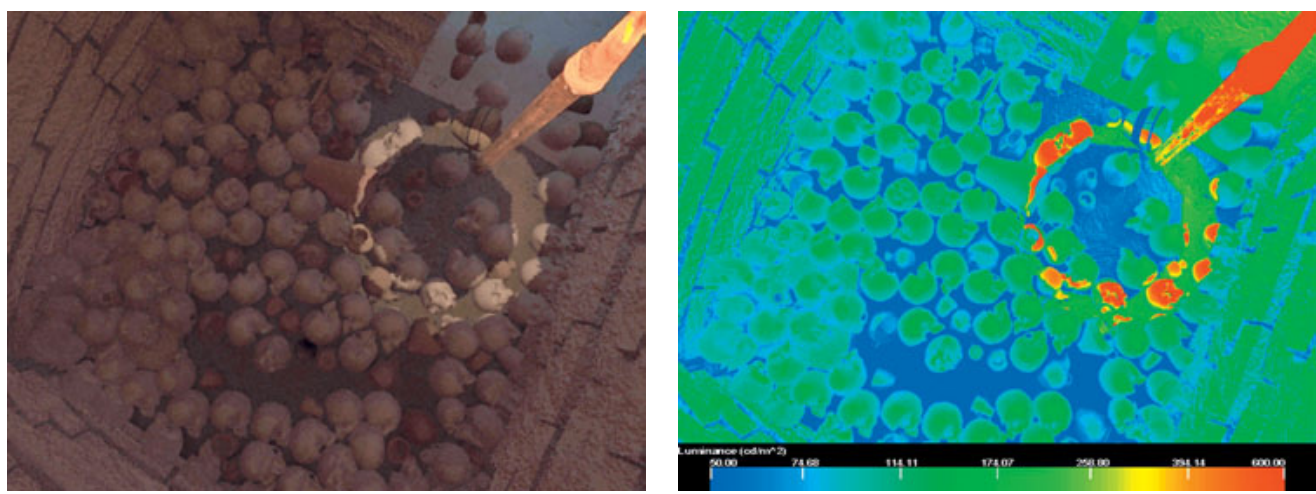

Figure 5 | Torch with intensity of 1500 candelas providing flame light of approximately $100 \mathrm{~cd} / \mathrm{m}^{2}$ on 30 th October 2007 at 7 a.m. First phase of Burial Building I9. 
ferences in comparison to modern practices, indicating how superficial our interpretations may become when they are solely based on contemporary comparators.

Polythyra and light-wells in Minoan architecture created a distinct contrast between light and shadow, whilst the variety of colour and decorative schemes produced a feeling of constant motion. The contribution of light is at its most apparent in Minoan palatial structures, which contrast considerably with domestic spaces. The information we have concerning urban settlements and consequently domestic spaces mainly derives from the archaeological remains, supplemented by several depictions in art. Houses were two- or three-storey buildings, with most of the windows on the upper storeys, ostensibly for security and privacy purposes. Depending on the use of each room, there are varying features such as hearths and benches, coupled with light sources that correspond to functional interpretations of spatial practice based on the material culture. Thus, the largest room is usually the primary living space of each household. The smallest rooms seem predominantly to be used for storage and usually have only small openings for ventilation, with indirect illumination provided by the adjacent rooms. Similarly, the rooms used for industrial activities seem to have enough openings to provide light for practical purposes and to facilitate air circulation.

The lighting values obtained for the North House at Kommos seem to match those expected of a domestic space. The areas such as Ni6, identified as being where most of the everyday activities were taking place, such as food preparation and consumption, are well lit through doors and windows (figs. 6 and 7). Where necessary the amount of available light can be increased by using portable lighting devices, such as olive oil lamps. Storage rooms, such as room Ni and Area I8, have small openings, presumably to allow air circulation whilst restricting the impact of direct and bright indirect illumination on the goods stored (figs. 8 and 9). Similarly, areas that have been characterised as sleeping quarters are usually made of solid walls which do not allow any direct illumination. The indirect light coming from neighbouring openings can be considered enough for the activities taking place there and again additional light can be provided by lamps or torches. Lastly, the hearth in the main room (NI7) not only provided warmth but also light during night hours and on cloudy days (fig. I0).

\section{Lighting study three: the 'Ceramics Workshop' at Zominthos}

Zominthos is located in the mountains of central Crete. It was discovered in 1982 as part of an excavation which is still in progress by Efi Sapouna-Sakellarakis. A monumental Central Building that covers an area of $\mathrm{I}, 600$ square metres, developed from the i7th century onward, has been revealed. The structures are well preserved and some walls still stand at a height of 2.2 metres (Sakellarakis and Panagiotopoulos 2006). The purpose of this case study was to construct virtually a room unearthed at the northwest corner of the Central 


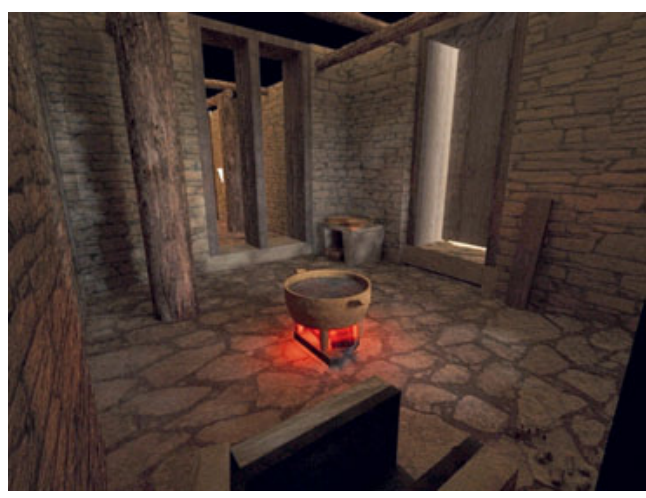

Figure 6 | Room Ni6 in the North House, Kommos Hilltop Houses. The finds indicate that food preparation and consumption was taking place in this room.

Figure 8 | Lighting analysis in a storage area, North House, Kommos Hilltop Houses. The values on 2Ist March 2010 at 3 p.m. suggest that light entering this area was insufficient for carrying out any activities requiring detailed near sight. It is appropriate for such spaces to have low lighting values, as this may have helped the preservation of the various goods kept there.

Figure 9 | Area I8 in the North House, Kommos Hilltop Houses. The space behind the staircase that led to the second floor might have been used for storing goods.

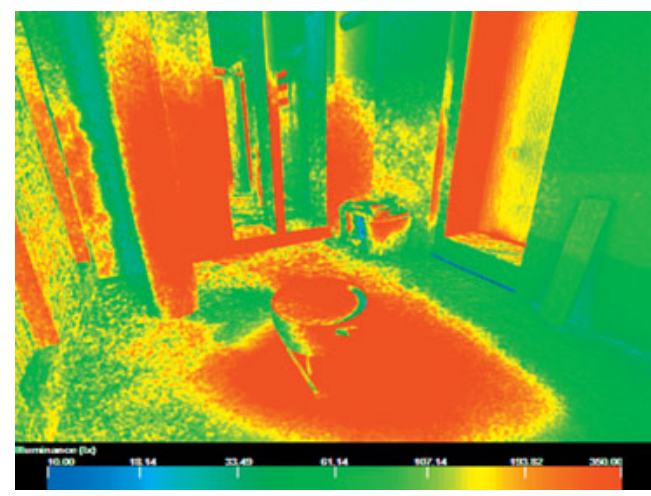

Figure 7 | Lighting analysis of Room Ni6 in the North House, Kommos Hilltop Houses. The values on 2Ist March 2010 at 3 p.m. indicate that light entering this area was sufficient for carrying out domestic activities.
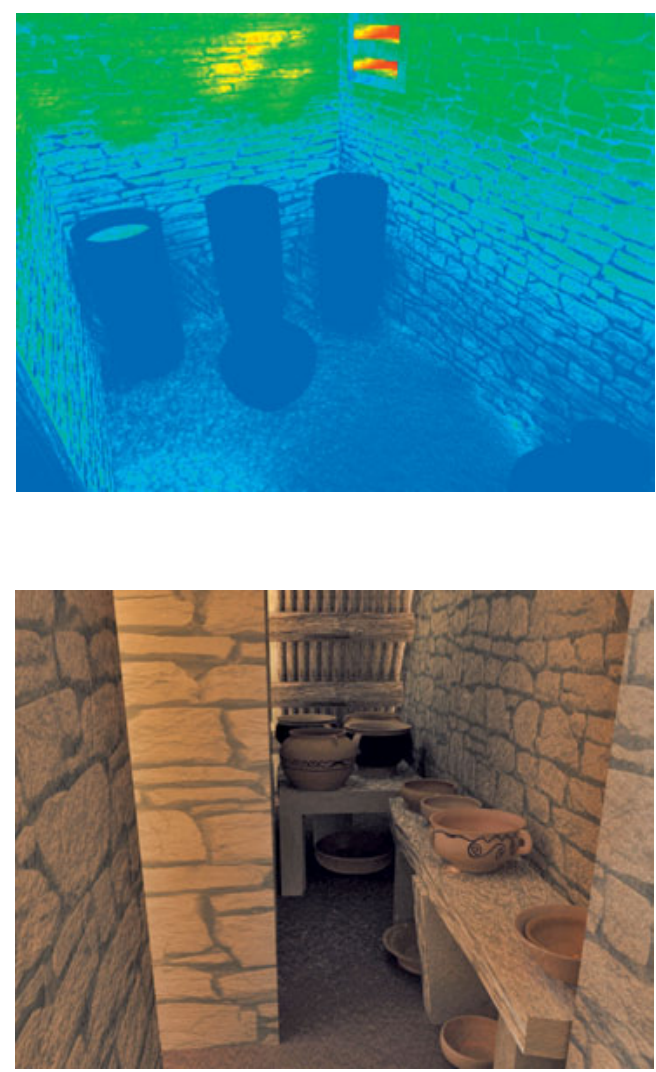


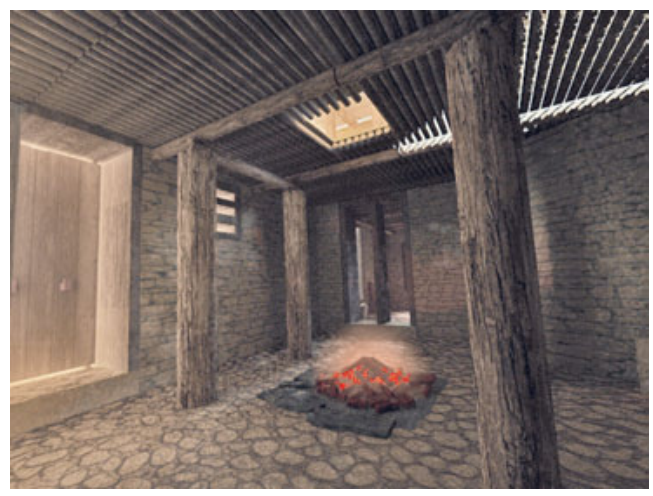

Figure 10 | Room Ni7 in the North House, Kommos Hilltop Houses. This is the largest room of the house. The hearth at the centre indicates that most of the activities were taking place in this room.

Building, Room I3, which has been identified as a Ceramics Workshop (fig. II). It defined a I5 square metre area that contained more than 250 vessels for everyday use, some bronze and stone tools, a basin in the middle of the room and a potter's wheel. Ceramics had been placed on benches running along the northern and southern walls, some of which were found in situ. Some of them may have been positioned on wooden shelves along the walls, as indicated by the great quantity of carbonised wood unearthed. Although Room I3 has provided a range of features which indicate its use as a ceramics workshop, there is one peculiar characteristic: although the walls are preserved to a significant height, no window was revealed. This is in comparison to known windows in the structure in the adjacent Rooms I4 and I5, as well as in Rooms 8 and 9 on the facade of the building. Thus, an illumination study was defined to reveal the extent to which an apparently weakly lit space could be used as a working area.

According to several ethnographic comparators from regions of Crete and mainland Greece with a strong tradition in pottery making, potters' workshops should be illuminated by sufficient sunlight to facilitate the production of ceramics. In Margarites for example, a small village to the east of Rethymno, ceramics workshops used to have at least one large window and a door, which remained open during the production of pots. During the study it becomes apparent that every single working space should have enough light to assist people's work. When natural light is not adequate, flame illumination can be used to increase the lighting levels. However, the kind of light that is produced from flame sources, such as a candle or an oil lamp, is a combination of light and shadows. The study identified that this flickering, variable illumination hinders any work which requires absolute control of the product created. The possibility of the flickering providing an enhanced appreciation of the subtle morphology of the ceramics when produced was not supported ethnographically.

The level of preservation of the main walls in Room $\mathrm{I} 3$ is exceptional for such a structure, leaving no room for hypotheses about the preservation of any openings in them. However, small window openings may be hypothesised to have existed in the upper courses of 
Figure 11 | Aerial View of the 'Ceramics Workshop'.

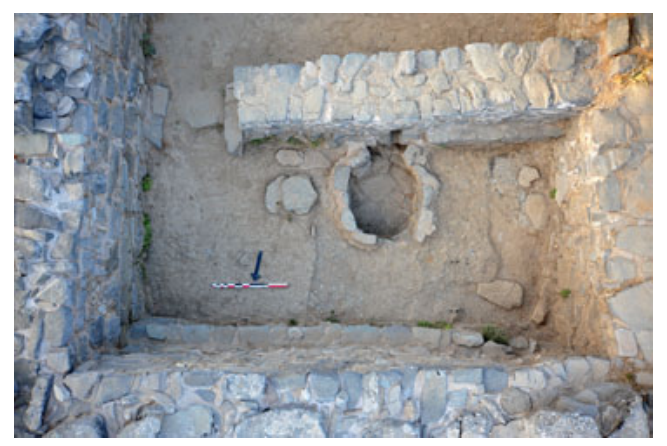

the walls which do not survive intact. It is not impossible to have had small openings facilitating the illumination and ventilation of the interior here. For this reason, several structural models were produced in order to provide a reliable illumination study regarding the impact that this unusual absence of windows may have (fig. I2). Small windows were constructed in the east and west walls of the room, corresponding to those found in rooms 7 and 8 , and I4, I5. In addition, oblong windows were created in the north wall, and various alternatives were examined with the partition wall that divides Rooms I3 and I4.

The absence of windows was initially explained by the excavator, based on the fact that clay is a very fragile material and, as a consequence, a ceramics workshop should not be overlit or have constant air circulation, since clay can easily become dry and useless. He also supported this idea by stating that the windows in the adjacent rooms may have provided sufficient light to aid a potter's work. Although it was impossible to test this idea physically, since the structures are not fully preserved, the computer graphic simulation produced provided the chance for a further analysis of this dataset. The results of the lighting study undertaken indicate that no light could enter the room through nearby openings, as the values obtained do not exceed 40-50 lux in the spring and summer months (fig. 13). With windows in the north, east and west walls there is increased illumination ranging from $o$ to 70 lux (fig. I4). However, none of them seem to have facilitated the diffusion of light to a sufficient extent to consider these alternatives a solution to the problematic aspects of the dataset. The walls' thickness, which at some parts exceeds one metre, seems to have prevented the significant ingress of daylight to the interior. Flame illumination was also tested (fig. I5), although as discussed this was discouraged, since modern potters argued that the existence of flames in a dark room produces irregular shadows which confuse the potters about the actual form and shape of the vessel produced.

Through this illumination study, which would have been impractical by other means, it was proven that neither the light coming from adjacent openings nor the addition of hypothetical windows can be considered sufficient to consider this area a continuous working space. The initial interpretation has to be re-evaluated based on the archaeological finds, ethnographic correlates and the results of the lighting analysis (Papadopoulos and Sakella- 


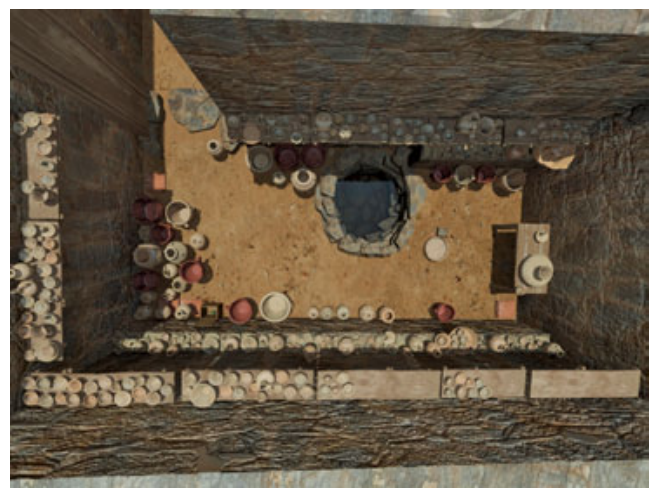

Figure 12 | 3D graphic simulation of the 'Ceramics Workshop'.
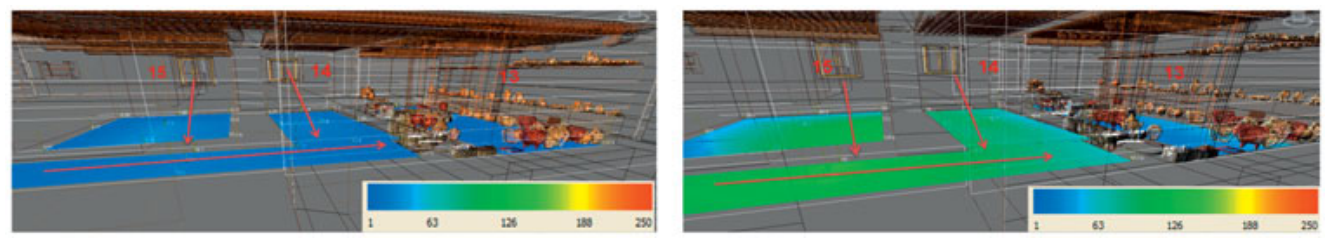

Figure 13 | Light meters indicating the amount of incident light (illuminance) entered in Room 13 from the openings of the adjacent rooms. Left: 2Ist December 2010 at 9 a.m., Right: 2Ist March 2010 at I2 p.m.

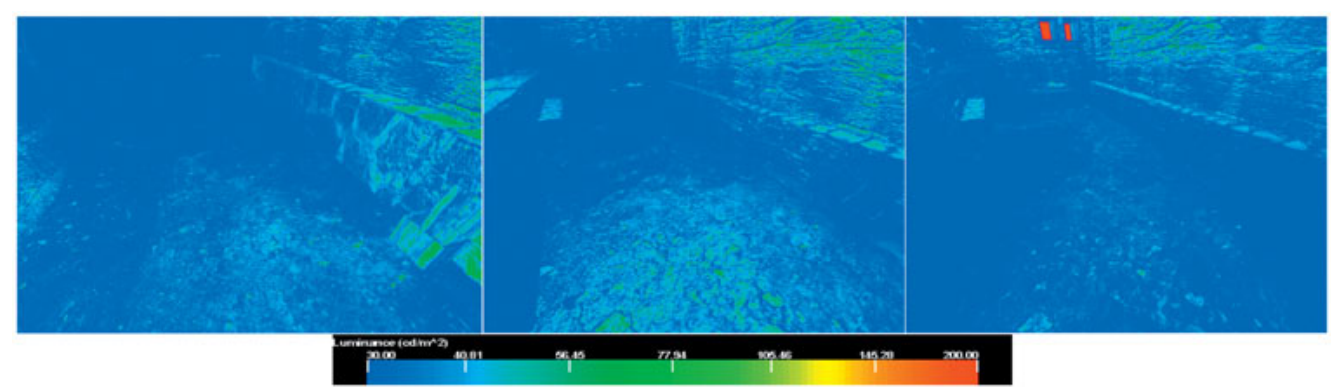

Figure 14 | Lighting analysis with luminance values not exceeding $70 \mathrm{~cd} / \mathrm{m}^{2}$ (left-right): window on the north side, window on the east side, window on the west side. The test date is 2I. 6. 2009 at I2 p.m.

rakis 2013). The latter may suggest that Room I3 was a room for storing and drying the vessels that were produced somewhere else in the Central Building and most probably outside this room, where a kiln and more than roo vessels were found. It is possible that, as is the case with traditional Cretan potters, a small shack was constructed with perishable materials in the vicinity of Room I3. This could then have been used as the potter's working space, providing direct access to the kiln, natural resources and sunlight. 

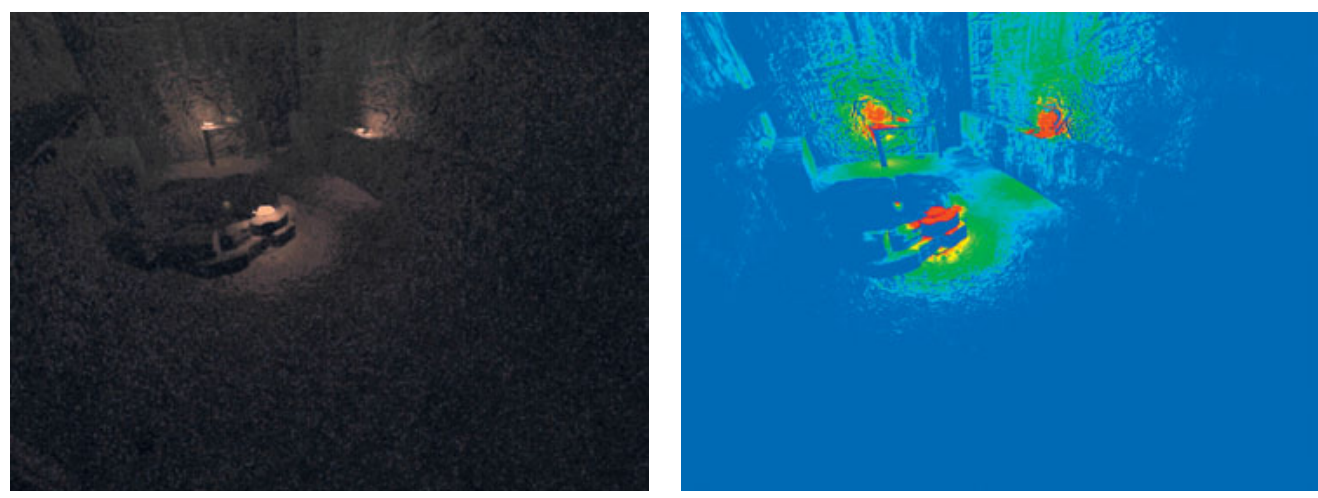

Figure 15 | The 'Ceramics Workshop' under the light of three olive oil lamps. Lamps provide local illumination, while creating irregular shadows, which may confuse the potter in the production process.

\section{Discussion}

Computer methodologies provide valuable tools for exploring the complexities that the archaeological record presents. The illumination of an ancient interior space can only be examined via physical reconstruction and experimental archaeology, and through formal lighting analysis within a computer graphic simulation. These two methods necessarily work in parallel. A physical construction is often expensive and requires a broad range of construction expertise. It also requires the production of one or a small number of variations on any given variable. However, the physical simulations provide a useful source of lighting information and crucial data to enable direct comparisons to be made with the lighting simulation. This approach has proved successful in our work at Çatalhöyük, where the initial computer simulations were calibrated against lighting data and polynomial texture maps gathered in a physically constructed 'experimental house' on site (Earl et al., forthcoming a; Earl et al. 20I0). For lighting analysis of this kind to develop there must continue to be experimental archaeology to provide the necessary luminaire and material information. Similarly the construction of computer models requires detailed input from architectural and engineering experts in order that the geometry produced is physically and culturally accurate.

The three lighting examples presented, from three different contexts, clearly show that, depending on the use of each building or area, distinct lighting conditions are needed in order to facilitate the activities that take place in them. It may not be possible to give definitive answers, but the various results provide invaluable stimuli, which can be used as a fertile field for discussion. There has been some criticism of the use of contemporary lighting metrics in the calculation of suitability for specific tasks. Dawson et al. (2007) did not define new luminaire light distributions or spectra for their light sources and instead 
used a standard modern luminaire. We agree that this may not have significantly impacted their results. Their use of standard CIE and other tables alongside ethnographic data for evaluation of the capacity to perform given tasks is more problematic (e.g. Woodson I992). Again Dawson identifies the problems with these data and covers the implications for their use in great detail. The use of such metrics carries with it problematic issues of essentialism in terms of perception, but we would argue that these are in any case at the heart of such analyses, and indeed in much archaeological writing relating to the senses.

However, it should be argued that the interpretive process that usually follows an archaeological research project may embroil or oversimplify past reality. Social factors may be misinterpreted because of our own social criteria, cultural traditions may be misunderstood due to our modern westernised way of thinking, values and world views, and structural remnants may be considered self-explanatory evidence of the various processes that have taken place. As a fundamental feature of our archaeological practice we always try to use well documented correlates with a definite resemblance to our primary datasets. In this way we aim to approach the past more closely. Still, in the work described here we have drawn back from the use of formal metrics, and our interpretations instead draw explicitly from contemporary personal experience in physically constructed ancient and modern environments, and on ethnographic data. We consider this interaction between formal methods and lived experience to be a fundamental aspect of archaeological practice. However, we acknowledge the value that such standard measures of recommended lighting conditions offer as a structure for interpretation.

The three studies demonstrate that the possibility of consistent variance of parameters within computer graphic simulations, as opposed to physical environments, enables crucial sensitivity analysis to be undertaken. This testing allows lighting and visibility analyses and visual representations of spaces to be validated, both qualitatively and quantitatively. Whether through hand modelling of varying geometry, batch-processed variation of parameters or through the use of procedural modelling (Haegler et al. 2009; Müller et al. 2006), such sensitivity analysis is a crucial component. The impact of portable material culture such as blinds and screens, the varied location and intensity of artificial luminaires, different colour and intensity perception in humans, and the orientation of people, colourful fabrics and furniture all play a role in the pattern of light and shade. However, with every additional parameter introduced, the calculations required in producing comprehensive analyses increase by an order of magnitude, hence requiring increased use of Iridis 3 in our further work in this domain. Such a need for parameterisation will also feature in the next section as we consider the ways in which we can supplement the formal analysis of lighting with the formal analysis of visibility. 


\section{Visibility in computer graphic simulations}

In the second part of this paper we explore a companion method for formal analysis of these Minoan built structures. Whilst lighting studies provide an indication of the types of activity that could be performed in given locations and the relationship between form and perception, they do not provide an analogue to the sense of space typically defined in architectural studies of surviving built environments. In a context such as Herculaneum, where significant proportions of the built architecture survive, it may be possible to develop interpretations that draw directly from experience of the environment. As one moves further from this degree of preservation the extent to which one may talk about spatial sensations such as enclosure and transition is reduced, or at least rendered more complex. Despite this, studies continue to develop spatial interpretations on the basis of data that are themselves divorced from the forms they represent: namely the plan and elevation. In this section we will consider an alternative means for approaching the question of built space focused on patterns of visibility.

Formal visibility methods attempt to sample the visibility of a space or landscape. In GIS this accounts for the changing convex topography, but not enclosed and concave surfaces. Other approaches such as that defined here can account for visibility in built environments that elicit all of the complexity seen in the lighting studies above. In combination these methods make possible a summary of a space that is at once about the potentials of movement and sight, and the influences upon it imposed by structural form and illumination. Both approaches are also based in tradition and vocabulary associated with the production of engaging visuals, and hence we are able to intermingle the creative, inherently subjective processes of modelling with the metrics of formal spatial analysis.

\section{Texture viewsheds}

The texture viewsheds methodology was introduced in Earl (2005). The technique is based on the texture-baking algorithms common to computer games production. For the purposes of analysis this algorithm is used to define a metric for visibility for all surfaces within a $3 \mathrm{D}$ environment, including the distance from which the surface is viewed, the angle of view and the overall degree of visibility. The paper drew a great deal from the increasing overlap between GIS and computer graphic approaches. In essence the texture viewshed approach thus combined the formal raster mathematical components of GIS with the geometric capabilities of modelling software such as $3 \mathrm{ds}$ max. This same combination of techniques was employed by Paliou and Wheatley (2007) for the study of Akrotiri. They fall within a wide range of techniques for mathematically summarising the built environment, including Benedikt (1979) and Yang et al. (2007). Cf. Paliou et al. (20II) for detailed coverage. 
Since this initial publication the texture viewsheds approach has developed in two directions. First, there has been a realisation that approaches so dependent on modelled geometry must take account of the uncertainties inherent in it. An approach to undertaking a sensitivity analysis of this geometry, analogous to the production of fuzzy and probabilistic viewsheds in GIS, was outlined in Paliou et al. (2OII). In this approach consistent variation is introduced in duplicates of the geometry underlying the analysis. This is produced manually and the visibility products then compared. This method provides a great deal of control over the construction of models. However, this is necessarily limited by modelling resources in terms of the scope of variation. As defined above, the variation in lighting values for reconstructed archaeological environments is considerable, even given relatively subtle changes in model morphology. For this reason we have instead proposed a method employing procedural modelling tools to define variability in object components.

The second departure from the method outlined in Earl (2005) has been a move away from GIS-based analyses towards image-processing tools. The technique has moved from raster calculation in ArcGIS to an approach based around the established and robust VIPS framework (Martinez and Cupitt 2005; Cupitt and Martinez 1996). The overall technique remains computationally intensive in the production of graphical outputs and has therefore been optimised for processing on Iridis 3 .

\section{Visibility study: Kommos, a Minoan Harbour - the North House}

The lighting study of the North House described above identified functional zones on the basis of material culture and the pattern of light and shade observed within this building. Through the calculation of texture viewsheds we have attempted to correlate the morphology of the scene to the pattern of illumination.

The texture viewshed approach uses a moving omnidirectional light source to simulate the monocular vision of a single observer able to look in any direction. The pattern of visibility for this observer is then calculated by capturing the illumination values for all surfaces within the model. As the omnidirectional light provides the only illumination within the analysis and no indirect illumination calculations are made, those areas that have an illumination value greater than zero must be visible to the observer. The surface materials used for the lighting analysis of the North House were replaced by a simple shader with no reflectivity and even shading between vertices. As the shading model used in the calculation generates a linear fall-off from a value of 255 at a point perpendicular to the observer position to a value of $o$ at a point parallel to it, it was also possible to identify the angle of view to provide a more nuanced indication of visibility (Earl 2005). Furthermore, by limiting the exigent light via a photometric web distribution the technique enables particular angles of inclination to be isolated (Paliou et al. 20II). For the analyses presented below the resulting light maps were reclassified to create a binary texture viewshed (Earl 2005), where 
the pixels mapped to each geometric object were reclassified to values of I for visible and o for invisible.

The North House analysis began by defining the range of these potential observer positions within the house. By carrying out the analysis for multiple observer positions a summary of the whole space is defined. In this case study rooms Ni6 and NI7 were examined, with observers placed at one-metre intervals throughout the rooms. Two observer heights of I.Im and I.6m were specified to include observers at seating and standing heights (fig. I6). This generated a sample of 48 viewer locations. In other studies we have undertaken much denser observer samples (Earl 2005), but this was not considered necessary here as the focus was on the comparison with lighting analysis.

The model of the North House was modified to a limited degree to suit the needs of the methodology. As the texture viewsheds approach relies on the automatic unwrapping of planar surface lighting maps from geometry, it assists in post-processing if the geometry corresponds only to the areas visible to a potential observer. In other words it must be a water-tight model in which there are no overlapping meshes and redundant faces have been removed. As this modelling requirement also matches that imposed by accurate calculations of indirect illumination, it did not require a great deal of modification. Secondly, since the lighting maps are scale-independent, it is preferable for the individual geometric components to be similar in size. Again this does not present modelling difficulties, and the results below have in any case been standardised by object area.

Texture viewsheds were produced at a resolution of $1024 \times$ I024 pixels for the 60 objects in Rooms I6 and I7 of the North House model, based on a total of 2880 unwrapped lighting maps. This produced an average sample resolution of c.4 pixels $/ \mathrm{cm}^{2}$ of real-world object space. The maps were converted to binary maps showing visible and invisible components and then combined to produce texture viewsheds. The histograms of these were stretched uniformly according to the maximum visibility within the scene to enable optimum interactive display to be achieved in the viewport. The analyses below are based on the original data. Figure I7 shows a view of Wall 3 in Room I7. Figure I8 shows the binary texture viewshed for this wall and Figure ig shows the texture viewshed mapped back onto the geometry in the scene.

\section{Results}

When all texture viewsheds were mapped back onto the model of the North House, it became clear that there were very different patterns of visibility within the building. By replacing the textures used for analysis with the texture viewsheds it was possible to identify patterns in visibility by moving around the structure (fig. 20). In particular there was considerable influence of the supporting beams and the doorways in Room NI7 on the visibility in that space and the connected side spaces. Based on the observers within Rooms NiG and 
$\mathrm{NI7}$, the other storage spaces were not well integrated visually and the influence of varying heights of doorways and tight corners was considerable.

The metric data support these qualitative assessments of the remapped texture viewsheds. Room Ni6, which was interpreted as having a habitual domestic function, had a reasonable level of visual integration (table I). Whilst the sample size was low in this case study there was good visibility of most parts of the room from both within and without. The more central, communal Room NI7 had even higher levels of all round visibility (table 2) and was more tightly integrated into Room Ni6. Whilst Room Ni6 had an average of $26 \%$ of objects viewed by observers in Rooms Ni6 and NI7, Room Ni7 had $48 \%$. This implies that the latter was a considerably more prominent space, whether when standing or sitting. There are two potential factors that may have skewed these data. First, objects with larger surface areas may as a consequence become more prominent. In fact a comparison of the percentage of observers seeing each of the main wall and floor objects, compared to the observer density for the object, suggested that there was no simple correlation (table 4). Second, the number and location of observers in each room does not define the pattern.

In addition to general patterns there were distinct variations between comparable areas in the rooms, suggesting that there may have been areas more suited to particular forms of activity that require prominence, or from where it was important to be able to see the remainder of the house. Further lighting studies may assist in understanding these distinct areas. Whilst additional work remains to be completed, and in particular the incorporation of a larger density of samples and of probabilistic geometry, the results to date imply a differential sense of prominence between these two spaces.

\section{Conclusions}

The integration of formal visibility and lighting analysis methods has identified a number of points of interest to archaeologists studying the Minoan built environment. In the case of the North House at Kommos the integration of visibility and lighting analysis with visual analysis provided by rendered graphics has produced a synthetic understanding of the potentials of this space. Whilst this example provides only a relatively low-resolution case study, it is clear that the combination of methods merits further work. The ability to repurpose geometry produced for any one of the three approaches for use in the other two is extremely powerful, and in future work we aim to simplify further the modelling and analytical steps involved. We are also further exploring the possibilities for procedural modification of geometry as a means to qualify the impact of modelling decisions on the qualitative and quantitative outcomes.

The analyses defined above are clearly biased towards visual components of perception (for a critique on the dominance of vision in spatial analyses see Wheatley, this volume). Whilst such studies stimulate interpretation of a broader spectrum of senses (see for 
example Dawson et al. 2007's discussion of touch), vision remains predominant. Archaeology has always used a range of visual genres as interpretive aids. Sight is considered the sense of science (Classen I993) and ocularcentrism is usually privileged above other approaches (Jay I996; MacGregor I999). It is characteristic therefore that the three case studies under examination are all based on the assumption that visual perception would have been the critical sensory engagement of the Minoans. Although there are several attempts to consider other senses in archaeological contexts, both on a theoretical level and by technical means (Chalmers and Zányi 2009), the results remain limited. Only hearing has been introduced consistently in the realm of archaeological interpretation, although the outcomes have been challenged (Scarre and Lawson 2006).

As Paliou mentions in this volume, when space is studied only in two dimensions, certain social meanings remain under-appreciated and/or non-percept. Two-dimensional approaches of studying space fail to consider fundamental elements that might have influenced perception and human behaviour, thus limiting the interpretations to the relation between spatial configurations and human movement. To that we could add that two-dimensionality does not only pose problems for the interpretation of human-space relationship, since it is an issue ingrained in archaeological practice. In archaeology, we are used to producing two-dimensional realities, since the conventional recording mechanisms employed in excavations turn three-dimensional space into two-dimensional constructions (e.g. architectural drawings, photography, text). In other words, our work as archaeologists, or in this case as archaeological computing specialists, is based on the paradox that the material world has to be flattened in order to fit into the various methodologies employed, while three-dimensional computer graphic simulations are produced by using this two-dimensional information as a basis. In this process however, various perceptual, physiological and technical factors affect the course of interpretation, visualisation and reconstruction, therefore distorting the actual three-dimensional properties of the real world, leaving information behind, while adding others that might have never existed.

However, even three-dimensional approaches have certain drawbacks, since they tend to neglect other factors that played an essential role in the perception of a given environment. For example, to what extent could a formal multisensory analysis have provided a different perception of Burial Building I9? Could Zominthos' potter have been able to see by touch rather than vision, therefore invalidating our interpretation? Would the results have been different regarding the visibility of the Theran mural paintings or the interpretation of San Vitale (Paliou, this volume) if formal lighting analysis was incorporated (for the interpretation of ecclesiastical spaces based on the simulation of light, cf. Earl et al., forthcoming a)?

It seems likely that buildings and landscape design have been commonly influenced by the sensorium, but interpretation of them does not require an adherence to visual dominance or indeed to the active participation of all five traditional senses in a given encounter in space (Classen I993). The factor that Minoans might have ranked the senses differently or developed diverse sensoriums should not be underestimated. Especially in the case of 
Table 1 | Percentage of observers in Rooms Ni6 and Ni7 viewing objects in Room Ni6.

\begin{tabular}{|c|c|}
\hline Object & Observers (\%) \\
\hline Roof Beams3 & 88 \\
\hline Wall3 & 77 \\
\hline Ground Floor & $7 \mathrm{I}$ \\
\hline Wall7 & $7 \mathrm{I}$ \\
\hline Wallı & 63 \\
\hline Wall2 & 58 \\
\hline Roof & 40 \\
\hline Wall4 & 33 \\
\hline Roof Beams5 & I9 \\
\hline External Door & 4 \\
\hline
\end{tabular}

\begin{tabular}{|c|c|}
\hline Object & Observers (\%) \\
\hline Internal DoorI & $\circ$ \\
\hline Internal Door2 & $\circ$ \\
\hline Internal Door3 & $\circ$ \\
\hline Roof BeamsI & $\circ$ \\
\hline Roof Beams2 & $\circ$ \\
\hline Roof Beams4 & $\circ$ \\
\hline Supporting BeamI & $\circ$ \\
\hline Wall5 & $\circ$ \\
\hline Wall6 & $\circ$ \\
\hline Window & $\circ$ \\
\hline
\end{tabular}

Table 2 | Percentage of observers in Rooms Ni6 and Ni7 viewing objects in Room Ni7.

\begin{tabular}{|c|c|}
\hline Object & Observers (\%) \\
\hline Roof BeamsI & 90 \\
\hline Wall2 & 77 \\
\hline Ground Floor & $7 \mathrm{I}$ \\
\hline Wall 3 & 67 \\
\hline Wall5 & 67 \\
\hline Wall4 & 65 \\
\hline Roof Beams2 & 63 \\
\hline Roof Beams3 & 54 \\
\hline Roof Beams4 & 54 \\
\hline Roof Beams7 & 54 \\
\hline Supporting Beamsi & 54 \\
\hline
\end{tabular}

\begin{tabular}{|c|c|}
\hline Object & Observers (\%) \\
\hline Supporting Beams4 & 50 \\
\hline Supporting Beams3 & 48 \\
\hline Wallı & 48 \\
\hline Roof Beams5 & 46 \\
\hline Roof & 40 \\
\hline Roof Beams6 & 35 \\
\hline Supporting Beams2 & 35 \\
\hline External Window2 & I5 \\
\hline External WindowI & IO \\
\hline External Door & 6 \\
\hline Internal Window & $\circ$ \\
\hline
\end{tabular}

the 'ceramics workshop' at Zominthos, it might be argued that touch may have facilitated or indeed directed the potter's work, suggesting that a functional argument derived from lighting analysis must consider that pottery making may have been possible under dim or even flickering flame light. Such approaches cannot provide definitive answers. Although they encourage a further engagement and discussion of the datasets, they can be equally criticised for their tendency to pivot on philosophical rather than tangible arguments. For now we are content to continue exploring one or two aspects of perception as a means to critique the broader, socially contingent nature of space. Furthermore, we believe that an integrated approach that allows the creation of visual simulations, the analysis of potential visibility and the qualification of the lighting in space has much to recommend it. 
Table 3 | Comparison of percentage of observers seeing each of the main wall and floor objects compared to the observer density for the object. Note: there is no correlation between surface area of object and prominence of objects.

\begin{tabular}{|c|c|c|}
\hline Object & Observers per $\mathrm{m}^{2}$ & Observers (\%) \\
\hline Rest Wallsi & 2.6 & $8 \mathrm{I}$ \\
\hline Room I7 Wall2 & 1.09 & 77 \\
\hline Room I6 Wall 3 & $7 \cdot 4$ & 77 \\
\hline Ground Floor & 0.13 & $7 \mathrm{I}$ \\
\hline Roomi6 Wall7 & 3.09 & 7I \\
\hline Roof & 0.23 & 67 \\
\hline Room i7 Wall 3 & 0.52 & 67 \\
\hline Rest Walls6 & $\mathrm{I} .28$ & 67 \\
\hline Roomi7 Wall5 & I. 39 & 67 \\
\hline Rest Walls3 & $2.9 \mathrm{I}$ & 67 \\
\hline Roomi7 Wall 4 & 2.38 & 65 \\
\hline Roomi6 Walli & 0.44 & 63 \\
\hline Rest Walls2 & 2.33 & 58 \\
\hline Roomi6 Wall2 & 2.55 & 58 \\
\hline Rest Walls8 & 3.II & 58 \\
\hline Rest Walls4 & 1.08 & 54 \\
\hline Rest Walls5 & 0.42 & 52 \\
\hline Rest Walls7 & 3.43 & 50 \\
\hline Roomi7 Wallı & $0.3 \mathrm{I}$ & 48 \\
\hline Roomsi6 and i7 Roof & 0.25 & 40 \\
\hline
\end{tabular}

Figure 16 | View into NI7 showing the paths taken by the observers.

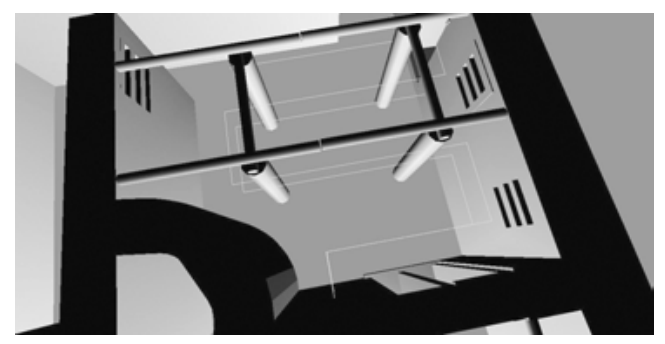



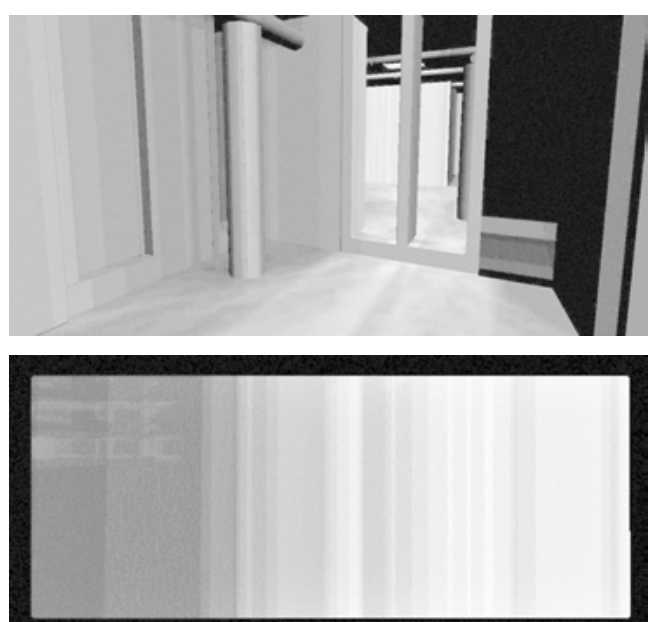

a.
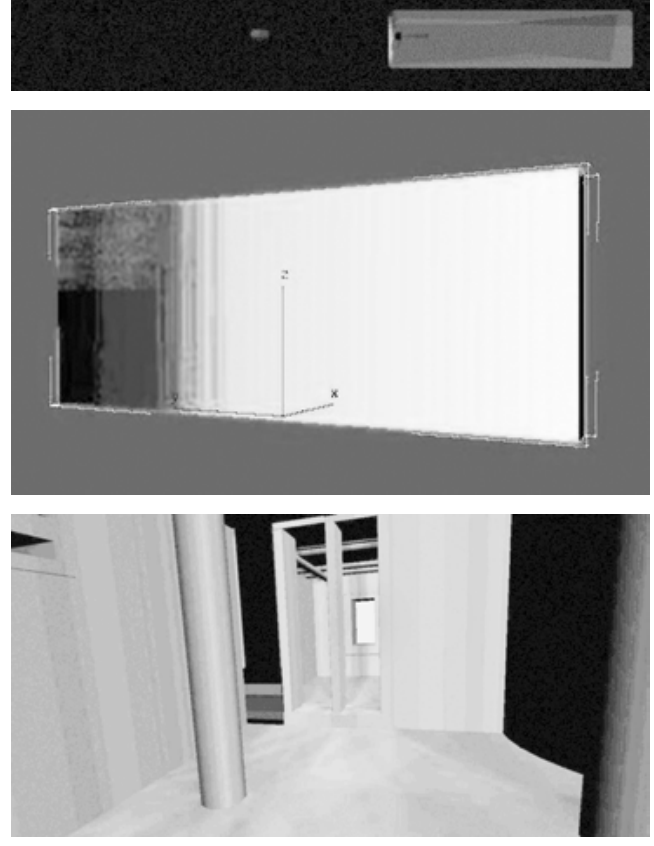

Figure 17 | View from Ni6 into Ni7 showing Wall 3.

Figure 18 | Binary texture viewshed for Wall 3.

Figure 19 | Wall 3 in model showing unwrapped texture viewshed.

Figure 20 | Looking back from NI7 into Ni6. 


\section{Bibliographical references}

Beale, G., and Earle, G.P. (20I0)

"The Herculaneum Amazon: Sculptural Polychromy, Digital Simulation and Context", in: A. Moore, G. Taylor, E. Harris, P. Girdwood, and L. Shipley (eds.), Conference Proceedings, TRAC 2009, pp. 31-40.

Benedikt, M.L. (1979)

"To Take Hold of Space: Isovist Fields", in: Environment and Planning B: Planning and Design 6, pp. 47-65.

Blomberg, M., and Henriksson, G. (2003)

"Literary and Archaeoastronomical Evidence for the Origins of the Hellenic Calendar in the Aegean Bronze Age”, in: A. Maravelia, (ed.), Ad Astra per Aspera et per Ludum European Archaeoastronomy and the Orientation of the Monuments in the Mediterranean Basin. Papers from Session I.13, held at the European Association of Archaeologists Eighth Annual Meeting in Thessaloniki 2002, BAR International Series 1154, Oxford, pp. 53-70.

Boyce, R. P. (2003)

Human Factors in Lighting, London.

Callet, P., and Dumazet, S. (2010)

"Natural Lighting, Gilts and Polychromy of Notre-Dame de Paris Cathedral", in: A. Artusi, M. Joly-Parvex, G. Lucet, A. Ribes, and D. Pitzalis (eds.), Conference Proceedings, 11th VAST International Symposium on Virtual Reality, Archaeology and Cultural Heritage, pp. 63-70.

Chalmers, A., and Zányi, E. (2009)

"Real Virtuality: Emerging Technology for Virtually Recreating Reality", in: Becta, http://www.becta.org.uk (I4 February 20II).

Chalmers, A. (2002)

"Very Realistic Graphics for Visualising Archaeological Site Reconstructions", in: Conference Proceedings, 18th Spring Conference on Computer Graphics, New York, pp. 7-I2.

Classen, C. (1993)

Worlds of Sense: Exploring the Senses in History and Across Cultures, London.

Cupitt, J., and Martinez, K. (1996)

"VIPS: An Image Processing System for Large Images", in: Conference Proceedings, IST/SPIE Symposium. Electronic Imaging: Science and Technology, 2663, Very High Resolution and Quality Imaging, pp. I9-28.

Dawson, P., Levy, R., Gardner, D., and Walls, M. (2007)

"Simulating the Behaviour of Light Inside Arctic Dwellings: Implications for Assessing the Role of Vision in Task Performance”, in: World Archaeology 39, I, pp. I7-35.

Dawson, P., and Levy, R. (2005)

"Explore the Ideological Dimensions of Thule Whalebone Architecture in Arctic Canada", in: Internet Archaeology I8, I, http://intarch.ac.uk/journal/issuei8/ (21 April 2013). 
Devlin, K., and Chalmers, A. (200I)

"Realistic Visualisation of the Pompeii Frescoes", in: A. Chalmers, and V. Lalioti (eds.), Conference Proceedings, 1st International Conference on Computer Graphics, Virtual Reality and Visualisation, AFRIGRAPH, pp. 43-47.

Devlin, K., Chalmers, A., and Brown, D. (2002)

"Predictive Lighting and Perception in Archaeological Representations", in: Conference Proceedings, UNESCO World Heritage in the Digital Age, 3oth Anniversary Digital Congress.

Dobbins, J., and Gruber, E. (2013a)

"Illuminating Historical Architecture: The House of the Drinking Contest at Antioch", in: F. Contreras, M. Farjas, and F.J. Melero (eds.), CAA 2010 Fusion of Cultures. Proceedings of the 38 th Annual Conference on Computer Applications and Quantitative Methods in Archaeology, Granada, Spain, April 2010. BAR International Series 2494, Oxford.

Dobbins, J., and Gruber, E. (2013b)

"Modeling Hypotheses in Pompeian Archaeology: The House of the Faun", in: F. Contreras, M. Farjas, and F.J. Melero (eds.), CAA 2010 Fusion of Cultures. Proceedings of the 38 th Annual Conference on Computer Applications and Quantitative Methods in Archaeology, Granada, Spain, April 2010. BAR International Series 2494, Oxford, pp. 77-84.

Earl, G., Porcelli, V., Papadopoulos, C., Beale, G., Harrison, M., Pagi, H., and S. Keay (forthcoming a)

"Formal and Informal Analysis of Rendered Space: The Basilica Portuense", in: A. Bevan and M. Lake (eds.), Computational Approaches to Archaeological Spaces, Walnut Creek.

Earl, G.P., Keay, S.J., and Beale, G. (in press)

"Archaeological Computing for Recording and Presentation of Roman Portus", in: S.J. Keay and L. Paroli (eds.), Workshop Proceedings, The First Portus Workshop, Rome, March 2008, British School at Rome.

Earl, G.P., Martinez, K., and Malzbender, T. (2010)

"Archaeological Applications of Polynomial Texture Mapping: Analysis, Conservation and Representation”, in: Journal of Archaeological Science XXX, pp. I-II.

Frischer, B., and Fillwalk, J. (forthcoming)

“The Digital Hadrian's Villa Project: Virtual World Technology as an Aid to Finding Alignments between Built and Celestial Features", in: Conference Proceedings, XXXX Computer Applications and Quantitative Methods in Archaeology 2012.

Goodison, L. (200I)

"From Tholos Tomb to Throne Room: Perceptions of the Sun in Minoan Ritual", in: R. Laffineur and R. Hägg (eds.), Conference Proceedings, Aegaeum 22 POTNIA, Deities and Religion in the Aegean Bronze Age, The 8th International Aegean Conference, pp. 77-88.

Haegler, S., Müller, P., and Van Gool, L. (2009)

"Procedural Modeling for Digital Cultural Heritage", in: EURASIP Journal on Image and Video Processing. http://jivp.eurasipjournals.com/content/2009/I/852392/ (2I April 20I2).

Happa, J. et al. (2009a)

"The Virtual Reconstruction and Daylight Illumination of the Panagia Angeloktisti", in: K. Debattista, C. Perlingieri, D. Pitzalis, and S. Spina (eds.), Conference Proceedings, 10th VAST International Symposium on Virtual Reality, Archaeology and Cultural Heritage, pp. 49-56. 
Happa, J. et al. (2009b)

"Illuminating the Past - State of the Art", in: K. Debattista, C. Perlingieri, D. Pitzalis, and S. Spina (eds.), Conference Proceedings, 10th VAST International Symposium on Virtual Reality, Archaeology and Cultural Heritage, pp. 155-182.

Jay, M. (1996)

"Vision in Context: Reflections and Refractions", in: T. Brennan and M. Jay (eds.), Vision in Context: Historical and Contemporary Perspectives on Sight, London, pp. I-I2.

Maggidis, C. (1994)

Burial Building 19 at Archanes: A Study of Prepalatial and Early Protopalatial Funerary Architecture and Ritual, University of Pennsylvania (PhD thesis).

MacGregor, C. (1999)

"Making Sense of the Past in the Present: A Sensory Analysis of Carved Stone Balls", in: World Archaeology 3I, 2, pp. 258-27I.

Martinez, K., and Cupitt, J. (2005)

"VIPS - a Highly Tuned Image Processing Software Architecture", in: Conference Proceedings, IEEE International Conference on Image Processing 2, Genova, pp. 574-577.

Masuda, T., and Yamada, Y. (2004)

"Sunlight Illumination Simulation for Archaeological Investigation - Case Study of the Fugoppe Cave”, in: Conference Proceedings, 10th International Conference on Virtual Systems and MultiMedia. http://www.cvl.iis.u-tokyo.ac.jp/papers/all/687.pdf (2I April 20I2).

Müller, P., Vereenooghe, T., Wonka, P., Paap, I., and Van Gool, L. (2006)

"Procedural 3D Reconstruction of Puuc Buildings in Xkipché", in: M. Ioannides, D. Arnold, F. Niccolucci, and K. Mania (eds.), Conference Proceedings, 7th VAST International Symposium on Virtual Reality, Archaeology and Cultural Heritage 2006, Baltimore, Maryland, pp. I39-I46.

Paliou, E., Wheatley, D., and Earl, G. P. (20II)

"Three-dimensional Visibility Analysis of Architectural Spaces: Iconography and Visibility of the Wall Paintings of Xeste 3 (Late Bronze Age Akrotiri)", in: Journal of Archaeological Science 38, pp. 375-386.

Paliou, E., and Wheatley, D. (2007)

"Integrating Spatial Analysis and 3D Modelling Approaches to the Study of Visual Space: Late Bronze Age Akrotiri", in: Conference Proceedings, The XXXIII CAA 2005: Computer Applications and Quantitative Methods in Archaeology, International Conference, The World is in Your EYes, pp. 307-312.

Papadatos, Y. (1999)

Mortuary Practices and their Importance for the Reconstruction of Society and Life in Prepalatial Crete: The Evidence from Tholos Tomb G, in Archanes-Phourni, University of Sheffield (PhD thesis).

Papadopoulos, C., and Sakellarakis, Y. (2013)

"Virtual Windows to the Past: Reconstructing the 'Ceramics Workshop' at Zominthos, Crete”, in: F. Contreras, M. Farjas, and F.J. Melero (eds.), CAA 2010 Fusion of Cultures. Proceedings of the 38 th Annual Conference on Computer Applications and Quantitative Methods in Archaeology, Granada, Spain, April 2010. BAR International Series 2494, Oxford, pp. 47-54. 
Papadopoulos, C. (2010)

Death Management and Virtual Pursuits: A Virtual Reconstruction of the Minoan Cemetery at Phourni, Archanes, Examining the Use of Tholos Tomb C and Burial Building 19 and the Role of Illumination, in Relation to Mortuary Practices and the Perception of Life and Death by the Living, BAR International Series 2082, Oxford.

Papadopoulos, C., and Earl, G. (2009)

"Structural and Lighting Models for the Minoan Cemetery at Phourni, Crete", in: K. Debattista, C. Perlingieri, D. Pitzalis, and S. Spina (eds.), Conference Proceedings, 10th VAST International Symposium on Virtual Reality, Archaeology and Cultural Heritage, pp. 57-64.

Parisinou, E. (2007)

"Lighting Dark Rooms: Some Thoughts about the Use of Space in Early Greek Domestic Architecture", in: R. Westgate, N. Fisher, and J. Whitley (eds.), Conference Proceedings, Building Communities: House, Settlement and Society in the Aegean and beyond, British School at Athens Studies I5, pp. 213-223.

Parker, M. P. (1999)

The Archaeology of Death and Burial, Great Britain.

Roussos, I. (2003a)

Image Based Flame Lighting, University of Bristol, (PhD thesis).

Roussos, I. (2003b)

"High Fidelity Lighting of Knossos", in: D. Arnold, A. Chalmers, and F. Niccolucci (eds.), Conference Proceedings, 4th VAST International Symposium on Virtual Reality, Archaeology and Intelligent Cultural Heritage 2003, pp. 47-56.

Sakellarakis, Y., and Panagiotopoulos, D. (2006)

"Minoan Zominthos", in: E. Gavrilaki and Y. Tzifopoulos (eds.), Conference Proceedings, O Mylopotamos apo tin Archaiotita os Simera. Perivallon, Archaiologia, Istoria, Laografia, Koinoniologia, Rethymno, pp. 47-75.

Sakellarakis, Y., and Sapouna-Sakellaraki, E. (1976)

"Anaskafh Archanon", in: Praktika ths en Athinais Arxaiologikhs Etaireias, pp. 35I-385.

Sakellarakis, Y., and Sapouna-Sakellaraki, E. (1997)

Archanes: Minoan Crete in a New Light, vol. I-2, Athens.

Scarre, C., and Lawson, G. (eds.) (2006)

Archaeoacoustics, Cambridge.

Shaw, J., and Shaw, M. (1996)

Kommos I: The Kommos Region and Houses of the Minoan Town, Princeton.

Soles, J. (1992)

The Prepalatial Cemeteries at Mochlos and Gournia and the House Tombs of Bronze Age Crete, Hesperia Supplements 24, New Jersey, American School of Classical Studies at Athens.

Sundstedt, V. Chalmers, and A. Martinez, P. (2004)

"High Fidelity Reconstruction of the Ancient Egyptian Temple of Kalabsha", in: Conference Proceedings, 3 rd International Conference on Computer Graphics, Virtual Reality, Visualisation and Interaction in Africa, pp. IO7-II3. 
Trigger, G. B. (2006)

A History of Archaeological Thought, Cambridge, MA.

Woodson, W. (1992)

Human Factors Design Handbook: Information and Guidelines for the Design of Systems, Facilities, Equipment, and Products for Human Use, 2nd edition, New York.

Yang, P.P.J, Putra, S.Y., and Li, W. (2007)

"Viewsphere: A GIS-based 3D Visibility Analysis for Urban Design Evaluation", in: Planning and Design: Environment and Planning B 34, 6, pp. 97I-992.

\section{Zacharias J. (200I)}

"Pedestrian Behavior and Perception in Urban Walking Environments", in: Journal of Planning Literature, I6, I, pp. 3-18.

\section{Zányi, E. (2007)}

"High Dynamic Range Display of Authentically Illuminated Byzantine Art from Cyprus", in: D. Arnold, F. Niccolucci, A. Chalmers (eds.), Conference Proceedings, 8th VAST International Symposium on Virtual Reality, Archaeology and Cultural Heritage 2007. pp. 87-92. 
